\title{
Down the SoTL Rabbit Hole: Using a Phenomenological Approach to Parse the Development of Student Actors
}

\author{
ABSTRACT \\ Theatre is a multi-dimensional discipline encompassing aspects of several domains in the arts \\ and humanities. Therefore, an array of scholarly practices, pedagogies, and methods might be \\ available to a SoTL researcher from the close reading of texts in script analysis to portfolio \\ critiques in set, costume, and lighting design-approaches shared with the humanities and \\ the visual arts. For those studying the learning processes involved in developing actors, \\ however, this article argues that it is necessary to go beyond the cognitive elements of the \\ process and turn to the very experiential nature of performance to capture kinetic and \\ affective learning. While basic voice, movement, and acting skills can be built on repetition \\ and evaluated with critical rubrics, in order to capture the learning processes involved in the \\ integration of cognition, voice, body, and emotion (affect), we have to use the reflective habits \\ of mind present in theatrical culture. One approach to gathering reflective data for such \\ studies is phenomenology. This article describes several SoTL inquiries into the experiential \\ nature of performance. It argues that, depending on the research question at hand, \\ phenomenological reports on developing acting skills intersecting with demonstrations of \\ cognitive analysis and external performance critiques not only provide a rich data stew for \\ analysis but deeper insight into the learning processes of the developing performer.
}

\section{KEYWORDS}

acting theory, embodied experience, phenomenology, actor training

Theatre is a multi-dimensional discipline encompassing aspects of several domains in the arts and humanities. Therefore, an array of scholarly practices, pedagogies, and methods might be available to a theatrical SoTL researcher from the close reading of texts in script analysis to portfolio critiques in set, costume, and lighting design - approaches shared with the humanities and the visual arts. For those studying the learning processes involved in developing actors, however, we have to go beyond the cognitive elements of the process and turn to the very experiential nature of performance to capture kinetic and affective learning. This is not an easy task. While basic voice, movement, and acting skills can be built on repetition and evaluated with critical rubrics, in order to capture the learning processes involved in the integration of those skills with cognition and emotion (affect), we have to use the reflective habits of mind present in theatrical culture. This essay will explore how, in this context, SoTL inquiry can retrieve the elusive process behind this integration.

One possible approach to gathering reflective data for such studies is phenomenology. Moustakas (1994) states that the phenomenological researcher "identifies the 'essence' of human experiences concerning a phenomenon, as described by participants in a study," and that the method may "involve (s) studying a small number of subjects ... to develop patterns and relationships of meaning" (as cited in Creswell, 2003, p.15). The prominent contemporary theorist of acting, Phillip B. 
Zarrilli (2007), notes, "Whatever the flaws and problems of phenomenology, it is, arguably, one of the most appropriate methodologies to utilize when considering acting, since it does not begin with performance as the object of inquiry, but foregrounds the 'lived' embodied experience of the practitioner as central to its project" (p. 641). Since SoTL is centered on understanding student learning processes, analyzing student accounts of the experience of performance and contrasting them to critiques of those same performances from faculty, peers, or outside professionals is a striking example of combining a signature disciplinary pedagogy (critique) and disposition (reflexivity) in the service of SoTL research (see Klebesadel \& Kornetsky, 2009). While other methods might do for external assessments of results, they do not provide the means to probe the embodied performance experience that is integral to the actor's process. However, the intersections of phenomenological reports, external performance critiques, and demonstrations of cognitive analysis provide researchers with a rich data stew that can begin to address the various learning modalities of performers: repetition, vocal and physical expression, cognition and analysis, improvisation, and experiential reflection.

\section{THE ACTING PROCESS}

Traditionally, understanding of the acting process has been expressed à la Diderot (1830) as a "paradox," an internal/external opposition. Does repetition of outer technical skills create the actor's performance, or does an inner emotional state animate it? Does he/she really "feel" the character's emotional life, or is it all a well-rehearsed illusion? In the latter half of the $20^{\text {th }}$ century, this opposition was popularly expressed in the difference between the technically proficient approaches to creating a role exemplified by most English actors and the raw emotionalism of American actors trained in Lee Strasberg's Method, which emphasized character psychology. This was a variation of the acting theories of Constantin Stanislavsky (see Gordon, 2006), who is credited with articulating the acting processes necessary for the performance mediums of the $20^{\text {th }}$ century. While Stanislavsky did investigate the role of emotion in performance early in his career, his later emphasis was on an actor's choice of actions, a more technical approach but one which does not negate the presence of emotion.

At present, most academic actor training attempts to balance the two approaches which is a position encouraged by the latest developments in neurobiology demonstrating the complicated interdependence of mind and body. Emotions in this context are viewed as the mind's response out of stored experience to sensations registered by the body (see McConachie \& Hart, 2006; Lutterbie, 2011; and Kemp, 2012). Similar mind/body interactions are also at play in how the actor navigates theatrical space, gestures, and vocal expression. This places the bulk of the actor's process (emotional, vocal, and physical life) at the crux of Zarrilli's "embodied experience" (2007, p. 638). In his study recognizing acting as a phenomenological practice, Johnson states that "the relationship between the subject and environment within time is fundamental to understanding performance since it never takes place in abstraction, but only ever in a concrete context at a specific time" (2011, p. 68). For actors, embodied knowing involves consciously noting, however fleetingly, the sensations of one's body in motion, of intentionally committing to an action, of responding to given circumstances and other characters in the moment. While actors may have a memorized text and rehearsed blocking supporting them, to act is always to be operating in space and time. Sometimes one can retain the sensation of the moment, but mostly, describing it is an after the fact reflection. A study of embodied practices is therefore a complex and fragile reporting process, mapping the unfolding consciousness of the performer as they explore the given circumstances of the text, discover purposeful actions, determine character traits, and master performance dynamics. This inner process is only accessible to the performer. It is their experience, and 
to access it we must depend on the performer's reporting. However, the product of the process is on view in the performance and can be evaluated by an audience.

The implications for SoTL studies of actor development mean that the "rabbit hole" of embodiment will be central to the project and cannot be ignored or eschewed. While other disciplines use language to evaluate knowledge development, in acting language is not our primary medium--the body is. Thus the phenomenological project of "constructionism"--of finding a middle ground between objective and subjective reality--suggests our best means of capturing the student experience of learning to act. Both data from external critiques and student performers' perceptions (constructions) of their embodied experiences gained while evolving and exploring their creative processes should, therefore, be a part of any SoTL studies of actor development.

\section{SOTL DATA SOURCES FOR ACTOR DEVELOPMENT STUDIES}

This essay will outline the possible data sources for each of these modalities and the appropriate analytical tools to navigate those sources using examples from research projects carried out in the Theatre Department of Columbia College Chicago in the last decade. These projects were part of the on-going assessment program within the department and were designed to illuminate various aspects of the curriculum as they impacted student learning. In other words, their purpose was extremely practical - what we refer to as "everyday SoTL"--an intra-departmental tool to probe and test our pedagogies. While any department might deploy such an approach, in an unusually large department (between 750-800 majors, of whom over 650 are performers) it is a virtual necessity in order to track student experience, develop curriculum, and ensure outcome goals. A secondary incentive for the use of team SoTL research (which is the norm in the department) is development for both full-time and adjunct faculty. In addition, the issues of department size, variety of degree specialties, and wide diversity of student talent, cultural background, and previous experience provide a rich environment for broader studies of performer training that may be applicable to other schools, disciplines, and situations. McKinney (2007) points out that, while SoTL may be used for internal assessment, it is meant for "wide public external use ... adding to the literature and shared knowledge base and for faculty productivity via presentations, performances, and publications" (p. 11). Assessment in the Theatre Department at Columbia is mostly accomplished via a website that records faculty evaluations of student performance skills in every relevant class every semester. Both progress and end-of-semester attainments are noted with faculty comments for each prompt. This process not only allows tracking of individual and student cohort development over the entire skills curriculum, but it signals areas that may deserve deeper study. For those issues, we design a SoTL investigation. Several of these "everyday SoTL" projects have been disseminated to a wider audience, especially as they might be of interest to the discipline at large or even other fields. Faculty members also build on their SoTL experience to innovate training approaches for the rapidly changing, multi-media performance world our students face. For us, "everyday SoTL" is much more than an assessment tool; it is an on-going inquiry into the performance practices of both ourselves and our students.

Basic physical technique and vocal expression are learned primarily through the modality of repetition, and progress can be captured with evaluative rubrics and recorded exercises or performances. The former are usually a tool of in-the-moment assessment, while the latter allow for more considered analysis but require accounting for the mediation of the recording technology used which may distort perception of the performance. Cognitive understanding of the acting process and subsequent application to choices made in performance can, of course, be evaluated through written tests, essays, 
character analyses, and rehearsal journals. These will only illuminate the intention of application, however, and not the degree of execution. The latter will have to come from external critique. Improvisation can be considered the experiential research and development part of the acting process. It involves exploration and problem solving with in-the-moment application. Capturing this fleeting process is difficult but can be done with a clear structural rubric to critique choices and outcomes, videotaping of class work, and reflective discussions (also taped) or written responses done in the immediate aftermath of the work. Reflective reporting can also be gathered in focus group discussions, surveys, and in-depth interviews. Such materials can then be transcribed and subjected to grounded theory analysis, one of the basic analytical tools of phenomenological research.

\section{INTRODUCTION TO PROJECT EXAMPLES}

SoTL projects in the Department have ranged over several disciplinary areas but have mainly concerned two sorts of issues integral to performer training - the development of individual skills such as vocal dynamics or physical flexibility, and the development of integrated skills where the actor successfully combines cognitive understanding of the text with vocal, physical, and affective character responses to given circumstances in the moment. Depending on the question at stake in the former inquiries, data sources can range from video tapes of classes or performances, reviewers'/instructors' notes, and student process journals, surveys, and interviews. Over the decade, these inquiries have concerned the treatment of assimilation nasality by a team of voice faculty; the development of a music theory curriculum aimed specifically at the needs of Musical Theatre (MT) program students; the transfer and retention of basic acting process skills from one level of the curriculum (and semester) to the next; and the use of the "learning community" approach in facilitating the earlier integration of students' body movement and acting process skills. All of these projects resulted in changes to the curriculum or to pedagogy. The data from the Musical Theatre project was used to convince another department (Music) to create a specific theory class for MT students. The insights gathered in the "learning community" study laid the groundwork for a major overhaul of the introductory curriculum in the Department embodied in the Foundation Course described below.

All of the above studies had impact mainly on the curriculum and pedagogy within the Department, although two were presented as models for others' use at international SoTL conferences. While those studies mainly isolated the development of specific skills, the more difficult task for the SoTL researcher is tracing the process and pace of students' integration of those skills into a cohesive mastery in their performances. It is in these inquiries that the possibilities exist for using the experiential nature of embodied performance to shed light on the learning contexts and issues of other disciplines. The following studies attempt this in a variety of frameworks: following a particular integrative quality throughout a student's college program, studying the evolution of skills integration in the course of the rehearsal and performances of a production, and investigating how skills integration may take place at the beginning of the curriculum. ${ }^{1}$

\section{THE TRANSFORMATIONAL SKILLS STUDY}

The ability of an actor to transform him/herself vocally, physically, and emotionally from character to character is a prime example of a "meta" quality that can speak to the development of integration capabilities in students. My colleague, Jeff Ginsberg, and I conducted a year-long SoTL study both to explore the observable manifestations of transformational skills in our students and to garner evidence of students' own awareness of their learning process. While many of our talented students gave 
ample evidence of these skills, others had only minimal or inconsistent facility with them. Our goal was to find out how and when in the students' experience within or outside of the curriculum these skills were acquired in order to strengthen the pedagogy targeting these skills across the program. The study consisted of three sources of data: 1) expert panels of industry professionals evaluating audition performances, 2) in-class exercises targeting physical transformation skills, and 3) student focus groups discussing both the concept and the contexts of transformation in their training. The students involved were all seniors who had completed the BA requirements in the acting program but either opted to take the capstone acting class as an elective or were required to take it for the BFA degree. The audition panels and exercises were all accomplished within the first two weeks of three sections of the capstone class in fall, 2008 and spring, 2009. The twenty-six participants can, therefore, be viewed as a representative sample of the typical BA in acting graduate. The focus groups were voluntary and took place near the end of the semesters. Twelve of the twenty-six students were videotaped in groups of two, three, and seven as they responded to and discussed a set of prompts about transformation. The panel ratings and comments, the in-class exercise results, and the focus group tapes were then compiled and analyzed. The panel used a five-question rubric aimed at each individual transformative skill and an overall integration. Specific comments were also elicited for each question.

The panels rated students on the performances of two contrasting audition monologues, looking at the transformation between characters and of vocal, physical, and emotional life. The results showed that the industry professionals agreed or strongly agreed that over $60 \%$ of the students demonstrated effective transformational skills in their auditions overall. They were neutral about the skills of between 20 and $29 \%$ of the students, and felt that the rest were ineffective. The highest marks were given for the transformation of emotional life and the lowest for physical transformations. Most of the critical comments centered on physical skills as well, noting repetitive use of mannerisms and body shapes, insufficient use of the torso and spine, and choices that were tentative or didn't go far enough. The inclass exercise that focused on observation and recreation of physical life had similar outcomes.

The focus groups tried to unearth the students' own perceptions of these skills and of when and how well they thought they had acquired them. In analyzing their discussions, we considered the following thematic areas: 1) What they understood transformation to be, 2) What their processes for creating transformation or applying these skills to a role was, and finally 3 ) When and where in their development as actors they perceived themselves to have achieved such skill(s).

We found it interesting that the students who could best articulate the concept of transformation and describe the processes they used to apply it were those who best demonstrated that application. In other words, in our estimation the best actors were also the best at pinpointing the nature of the skills involved and illustrating them with examples. Those better actors also had fuller performance resumes, so it appears that "practice makes perfect!" This observation further problematized our analysis, raising the question as to whether those resumes reflected the student's ability to spend more time and effort on getting cast or really reflected more innate talent and therefore better odds at being cast. Unfortunately, our data didn't speak to this issue. It did tell us that the participants' comments suggested that their full understanding of this phenomenon had come only lately, at the end of their junior or beginning of their senior years, and often happened in an out-of-class, even off-campus, performance experience. They also singled out the specific classroom or performance experiences that they believed were effective in giving them insights into transformation or provided the opportunities to practice it.

74 Perkins, Kathleen. (2016). Down the SoTL rabbit hole: Using a phenomenological approach to parse the development of student actors. Teaching \& Learning Inquiry, 4(1).

http://dx.doi.org/10.20343/teachlearninqu.4.1.9 
The combination of critical rubrics and commentary with the reflective data from the focus groups gave us a deeper understanding of how we might strengthen our pedagogy to better facilitate transformational development. In its wake we encouraged faculty to put more emphasis on physical transformation earlier in the curriculum (a challenge taken up by the Foundations course), instituted more classroom exercises focused on practicing emotional shifts, and mandated faculty at all levels of the acting program to spend more time on exploring physical and vocal choices so students don't resort to default personal habits under pressure. In addition, we sought to add to the performance opportunities allowing students to practice these skills. In a department that already stages twenty to twenty-five productions a semester, finding space and personnel has been a challenge but is proceeding.

\section{THE EXTRACURRICULAR APPLICATION STUDY}

Because the application of these skills is so important and telling, the department has also sought to use SoTL methods in examining the learning processes contained in all those extracurricular productions. This kind of assessment is rarely done, but performing arts departments are more than ever under pressure to demonstrate that such learning does occur, can be evaluated, and could even be tied to the credit/tuition fulcrum so crucial in the financing of today's higher education. Columbia is no exception, in fact, with our heavy commitment to production as a major attraction of the department's program, clearly connecting the applied learning in production with the rest of the curriculum is a necessity. So, in spring of 2014, we experimented with collecting SoTL data in the midst of the rehearsal and performance processes of a production of Heartbreak House, written by George Bernard Shaw (Shaw, 1919) during World War I. This was a fully produced and budgeted production cast from the student body in a competitive audition. Students also designed the costumes and soundscape of the production and managed the backstage functions, but for this project we chose to focus on the learning outcomes among the cast and the staff members (stage managers and assistant director) involved in the entire rehearsal process.

Three skills-based learning outcomes were articulated for the study: 1) ensemble playing skills, 2) use of language (phrasing, rhythm, emphasis etc.) and dialect, and 3) mastery of comic timing and characterization. In addition, the study sought to evaluate the students' cognitive understandings of the ideas expressed in the play and how they perceive them connecting with their present world. Data sources included two sets of student questionnaires administered at the beginning and middle of the rehearsal process, detailed notes from the vocal/dialect coach, a production diary kept by the director, written critical response from theatre professionals attending the performances, and a video-taped focus group discussion with the cast following the closing of the production. A preliminary analysis of this data has begun to yield information about the development of both ensemble and language/dialect skills within a rehearsal situation where immediate application occurs as opposed to development in a classroom. Whether such patterns are specific to this production or might apply to similar production conditions will have to wait for further case studies.

Students' perceptions of their processes in coming to terms with the vocal and physical requirements of the play revealed insights into when they integrate these elements into the interpretation of characters. The rehearsal process in this case reversed their usual experiences of having a great deal of "table work" (discussion of text, character objectives, production concepts, etc.) at the beginning of the process and instead threw them into the physical blocking and vocal work of the text. The memorization process was accelerated as well, so that the students were essentially learning on their feet, finding actions and comic rhythms prior to the deep psychological analysis that is usually the first 
step in staging realistic texts and which, in this instance, came later in the detailed run-throughs of the production. In the focus group, they described how they responded to this and what it taught them about their personal processes. They also expressed surprise at how physically demanding this very "talky" show was. The following are sample comments from the tape of the group discussion:

On the sentence structure: "I had to learn to stop fighting the way it was written." On the physical requirements of the dialect: "Is anyone (else's) mouth hurting?" On the comic structure: "I had to get the jokes. I had to find the character. In order to find the character, I had to understand the jokes."

On the physical requirements of the performance: "It took me longer to understand it... it took me longer to analyze the script, but I thought that it was not going to be as physically exhausting as it was. After each show, I was dead tired!"

On character insights: "As a Shaw character, you must revel in your victories but silently hold a grudge over your defeats."

On the ensemble experience: "We shared energy." "We fed off each other." "If I do this a little more or less, someone else will pick up the slack."

On the play's theme: "All these people in this fantastic house... all they have to worry about is heartbreak."

As these remarks suggest, their perceptions of Shaw's work, of the historical period, and of comedy based in ideas and character rather than punch lines all changed by a considerable degree. The extensive notes from the voice coach mapped the incremental development of the cast's dialect skills, and the critical comments from the professional respondents overwhelmingly supported the cast's perception of their mastery of language and comic skills. The use of all of these data sources gives a nuanced and insightful picture of the applied learning happening in situ in the production process which we plan to expand in the future to other types of production experiences and to the curriculum.

\section{THE FOUNDATIONS COURSE STUDIES}

The SoTL process accompanying the development of the Foundations Course in the Department has been a necessarily fluid but nonetheless productive example of using SoTL data collection and analysis methods to try to support the roll-out of this extensive and curriculum changing course. SoTL data from previous projects (see above) contributed to the impetus for and initial planning of the course as a first-immersion integrative experience in theatre making for all incoming theatre majors. The focus of the pedagogy is a hands-on application of basic theatrical concepts and techniques, emphasizing ensemble creation in a devised performance setting. Originally encompassing nine credit hours, it is team taught in student cohorts of sixteen to twenty and covers a broad swathe of introductory content in theatre, including basic acting, voice, and movement skills and design concepts within a context of theatre history fundamentals. It is designed to integrate a large set of students (225-250 prospective majors) with wildly varied theatrical experience and college preparation into a department that emphasizes a curriculum of ensemble in applied productions. Two experimental sections were attempted in 2011, followed by six sections in 2012 and 2013. We reached full capacity of fourteen sections in fall of 2014, and the course has been redesigned utilizing the results of a SoTL study. It is now comprised of two semesters of six hours each. The first semester is required of all theatre majors and retains the broad conceptual outlines of the original nine-hour course. The second semester is required 
of all performance majors (actors, musical theatre performers, and directors) and focuses specifically on the integration of voice, body movement, and acting skills.

The first SoTL study on the course occurred in the second iteration of the course and focused on the main learning outcome of the integration of beginning technical skills (voice, movement, acting, design) with various concepts of theatre making (space, time, action, character). The course syllabus set out "integration days" after each conceptual unit for which the students prepared a devised ensemble piece responding to the material and the skill sets they' $d$ been exploring in the unit. These provided an opportune moment to collect data. Four of the six sections were selected to be sampled. The sections were chosen because each one had a section leader familiar with SoTL work (the result of all the team projects discussed above). Each of these sections videotaped their "integration day" assignments for the unit on time about three quarters of the way through the semester. In addition, the students were asked to write reflective responses at the end of the performances addressing their own experiences in creating their works. The faculty also wrote short critiques of the work focusing on the evidence of integration. These were then analyzed mainly for indications of whether that integration was not only present but that the students demonstrated awareness of it in their descriptions of their creative processes.

The following example taken from student reflections after the performances demonstrates understanding of the interrelationships of time/timing with performance and design:

Timing and tempo are not only important in performance aspects of a piece but also in the design of a scene. At one point, we decided to cut the lighting on the first actress completely because we wanted the focus to be on the second actress alone. We struggled to decide when it would be appropriate to make this change because we wanted it to enhance the scene rather than be distracting. Student $A$

Here is evidence of the collaborative process, and insights into how timing affects design as well as actor performance:

The time assignment created, in me, a better appreciation of the depth and spaces generated by adding an artful pause or sudden tempo change to a piece... In (my classmate's) and my scene from "Betrayal" the importance of constant motion was really pounded into our performance. Originally we had many pauses worked in to add an effect, but they really made the piece drag a little. With the movements added we were really able (to) create a good flow and exchange. The other skill we incorporated in the end was that of moving from one's core, rather than the limbs. Student B

This excerpt presents the student reflecting on how changes in her and her partner's movement strategy connected to their understanding of time:

If my classmate and I were to continue developing our scene... I would want to clean up the purpose behind our actions to make them more clear and concise. For example, when I have my line "... keep your hands to yourself buddy" and I proceed to push (him) away, I would want to change that and draw him closer to me while still maintaining contact. This would increase the feeling of discomfort arising between us, making the choice more interesting and engaging for the audience. Student $C$ 
This example highlights the student's sense of process and understanding of the possible dynamics of his choice of actions.

Overall, the students reported a deeper or changed response to or understanding of the elements of time/duration/rhythm involved in their work, and they supported their assertions with specific examples from their own or others' performances. Their responses also demonstrated an almost universal appreciation of the collaborative process and ensemble relationships forged in the assignment. Analyses of this project and of both the student and faculty experience in this course led to its redesign. In the spring, another SoTL inquiry will be undertaken to study the learning processes unfolding in the new second semester iteration of the course. The faculty is especially interested in exploring how the skills integration practiced there will impact the rest of the actor training curriculum. This example in particular illustrates the on-going, successive nature of SoTL inquiry as practiced in the Theatre Department at Columbia.

\section{CONCLUSION}

A decade of SoTL practice as described in the projects above demonstrates that the elusive, ineffable aspects of the development of performance skills, of "embodied knowledge" can, indeed, be captured utilizing a phenomenological lens. Reflexivity, rigorous critiques, and careful analysis can be interwoven to yield fascinating insights into student/performer perceptions. This information can then be used to guide pedagogy, to support the development of curriculum and long-term strategies, and to facilitate further student learning. In addition, the embedding of reflective practices within the active learning processes of the studio not only conditions students to a state of mindfulness in the explorations of rehearsal but also trains them to use metacognition to retrieve and learn from their performance experiences. Both are valuable tools for their growth as artists.

While this discussion has centered on using SoTL inquiry to capture the process of embodied learning in a performance art, it has implications for other disciplines as well. Investigators of student learning must certainly consider how students experience and construct their understanding of a disciplinary field as well as how they process the application of that understanding to disciplinary issues and everyday practices. The mind-body interaction implicit in these questions suggests that all fields should consider the experiential aspects of knowledge construction in their considerations of student learning. The practices of all the (embodied) performing arts, but particularly those of the actor, are uniquely situated in the phenomenological middle of objective and subjective experience to demonstrate how such inquiries might be accomplished.

Kathleen Perkins is an Associate Professor in the Theatre Department of Columbia College Chicago where she teaches acting and text analysis and coordinates both the BFA in Acting and the Department Assessment Programs. She was a scholar in the second cohort of the Carnegie Academy for the Scholarship of Teaching and Learning (CASTL).

NOTE

1. Because these studies were done for internal assessment purposes and used materials generated within classes or productions, IRB reviews were not required at my institution. Where focus groups were used, students were voluntary participants and signed permission acknowledgements. The quotations from Foundations students were part of an online Moodle thread available to their classmates as well as their faculty teams. 


\section{REFERENCES}

Bleeker, M., Sherman, J., \& Nedelkopoulou, E. (Eds.) (2015). Performance and Phenomenology. New York, NY: Routledge.

Creswell, J.W. (2003). Research Design: Qualitative, Quantitative, and Mixed Methods Approaches. (2 ${ }^{\text {nd }}$ ed.) Thousand Oaks, CA: Sage Publications.

Diderot, D. (1830). Paradoxe sur le Comedien. English translation by Walter Herries Pollock (1883). London: Chatto \& Windus.

Gallagher, S., \& Zohavi, D. (2012). The Phenomenological Mind. (2 $2^{\text {nd }}$ ed.). London \& New York: Routledge.

Gordon, Robert (2006). The Purpose of Playing: Modern Acting Theories In Perspective. Ann Arbor: University of Michigan Press.

Johnston, D. (2011). Stanislavskian acting as phenomenology in practice. Journal of dramatic theory and criticism, 26(1), 65-84.

Kemp, R. (2012). Embodied Acting: What Neuroscience Tells Us About Performance. London, England: Routledge.

Klebesadel, H. \& Kornetsky, L. (2009). Critique as signature pedagogy in the arts. In R.A.R. Gurung, N. Chick, A. Haynie (Eds.), Exploring Signature Pedagogies: Approaches to Teaching Disciplinary Habits of Mind (pp. 99-117). Sterling, VA: Stylus Publishing.

Lutterbie, J. (2011). Towards a General Theory of Acting: Cognitive Sciences and Performance. New York, NY: Palgrave-MacMillan.

McConachie, B., \& Hart, F. E. (Eds.) (2004). Performance and Cognition: Theatre Studies and the Cognitive Turn. London, England: Routledge.

McKinney, K. (2007). Enhancing Learning through the Scholarship of Teaching and Learning: The Challenges and Joys of Juggling. San Francisco, CA: Jossey Bass.

Moustakas, C. (1994). Phenomenological Research Methods. Thousand Oaks, CA: Sage Publications.

Shaw, George Bernard (1919). Heartbreak House. London: Penguin Books Ltd.

Zarrilli, P. (2007). An enactive approach to understanding acting. Theatre journal 59, 635-47.

Zarrilli, P., Daboo, J., \& Loukes, R. (Eds.). (2013). Acting: Psychophysical Phenomenon and Process. London and New York: Palgrave MacMillan. that this article should be available on open access under a Creative Commons Attribution License 4.0 International (https://creativecommons.org/licenses/by/4.0). The only constraint on reproduction and distribution, and the only role for copyright in this domain, should be to give authors control over the integrity of their work and the right to be properly acknowledged and cited, and to cite Teaching \& Learning Inquiry as the original place of publication. Readers are free to share these materials - as long as appropriate credit is given, a link to the license is provided, and any changes are indicated. 